\title{
Lateral torsional buckling of tapered steel I-beams with stiffener ribs
}

\author{
J. Kuś \& T. Maleska \\ Faculty of Construction and Architecture, Opole University of Technology, Opole, Poland
}

\begin{abstract}
A procedure for calculating the critical buckling moment of a web-tapered I-beam with stiffener ribs is proposed, using potential energy calculations using the RayleighRitz method. The solution identifies the critical moments where lateral buckling begins in simply supported, web-tapered steel I-beams with ribs. In particular, lateral-torsional buckling is considered in beams with tapered web, and with various numbers of stiffener ribs. Detailed, numerical, parametric analyses are carried out. Uniformly distributed design loads are considered across three cases: applied to the top flange, to the shear center, and to the bottom flange. A parametric analysis, of a tapered beam with ribs, demonstrates that tapering of both the web and stiffener ribs influences the critical moments more than tapering only the web.
\end{abstract}

\section{INTRODUCTION}

Tapered steel beams, with varying web heights or flange widths, are widely used in the construction of industrial halls. Varying the cross-section can gives significant economic benefits by optimizing materials use to match the uneven distribution of internal forces. Most often, the bending moments reach their maxima only locally along the length of the element; therefore, the cross-section can be reduced in places with lower bending moments. Such optimization reduces steel consumption, and hence reduces the overall costs.

Protection against the torsional buckling of elements with changing cross-sections has a significant impact on their load-bearing capacity. If a bar is insufficiently protected against lateral-torsional buckling, the general instability may reduce its load capacity.

Determining the critical load that initiates overall stability loss in beams with linearly varying web or flange sections is a current concern, due to the increasing use of these elements. Analytical solutions for the critical moments of tapered beams can be found in Andrade et al. (2007), Asgarian et al. (2012), Benyamina et al. (2013), (Kuś 2015), Hakan Ozbasaran, Tolga Yilmaz (2018). Recently, experimental results for lateral-torsional buckling of steel members were presented by Tankova et al. (2018).

The above-cited work is limited to the analysis of unbraced beams. Adding vertical stiffening ribs to beams with slender webs, however, greatly influences both the ultimate loadbearing capacity and the resistance to torsional buckling. This issue for prismatic beams was presented in Lindener (1996), where the influence of endplates at beam ends was analyzed for several load cases. The effect of box-type ribs on the critical LTB load when a single-beam is loaded by the end moments are presented in Chambers et al. (1977). Gosowski $(2003,2007)$ made a broad assessment of how both the ribs and box ribs affect on the critical loading of free-supported beams with bi and monosymmetric cross-sections, loaded with pure bending and concentrated forces.

This article provides a solution for the elastic critical torsional buckling of an unbraced beam with a tapered web, supported by a fork, with a continuous, evenly distributed load 
a)

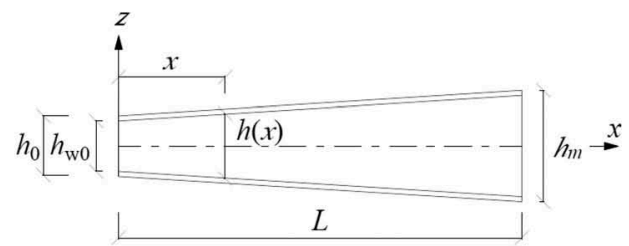

b)

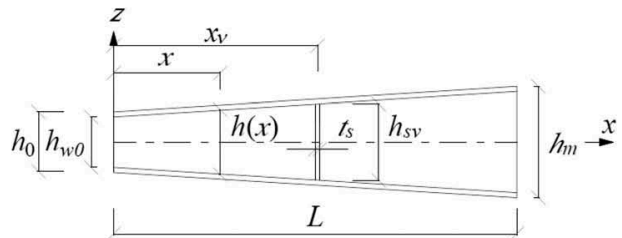

Figure 1. Tapered cross-section.

applied to the upper or lower flange, as well as to the shear center. Additionally, critical forces were calculated for a beam with the same geometric parameters, but with vertical ribs added for stiffening. The stiffening ribs were located along the length of the beam in different configurations. The Rayleigh-Ritz method was used to determine critical loads. In addition, a numerical example is given to illustrate the method, characterizing how the beam's crosssectional tapering affects the critical moments, as well as how the vertical stiffening ribs affect the critical load.

\subsection{Geometric characteristics of the cross-section of the beam with tapered cross-section}

The geometrical features of a beam with a linearly varying cross-section depend on the toe parameters determining their shape along the beam length. The taper parameter $\alpha_{T P}$, defined in equation (1) below, describes the change in web height, and also the change in the height of ribs along the beam length. For the tapered beam shown in Figure 1, the key geometrical characteristics can all be expressed as functions of the taper parameter:

$$
\alpha_{T P}=\frac{h_{m}-h_{0}}{h_{0}}
$$

Where $x$ and $z$ are beam coordinates, $h_{0}$ is height at the beginning of the beam, $h_{m}$ is height at the end of the beam, $t_{s}$ is the width of stiffening rib, $h_{s v}$ is the height of stiffening rib. Detailed geometrical features of the tapered cross-section can be found in paper (Kuś 2013).

\section{POTENTIAL ENERGY OF THE TAPERED CROSS-SECTION BEAM}

The potential energy for an I-beam with linearly variable cross-section (Figure 2), loaded with transverse forces on its length, is presented (Kuś 2013, 2015):

In Figure 2 and in the discussion below, $u, v, w$ are the displacement components of the shear center in the $x, y$ and $z$ directions, and $\theta$ is the twist angle.

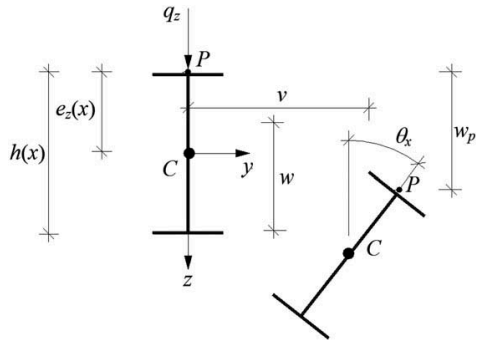

Figure 2. I-Section under lateral-torsional buckling. 


$$
\begin{aligned}
& \Pi_{L T B}= \\
& \frac{1}{2} \int_{0}^{L}\left(E I_{Z}(x)\left(\frac{d^{2} v}{d x^{2}}\right)+G I_{T}(x)\left(\frac{d \theta}{d x}\right)^{2}+E I_{\omega}(x)\left(\frac{d^{2} \theta}{d x^{2}}\right)\right) d x+ \\
& \frac{1}{2} \int_{0}^{L}\left(E I_{Z}(x)\left(\frac{d h(x)}{d x}\right)^{2}\left(\frac{d \theta}{d x}\right)^{2}+h(x)\left(\frac{d h(x)}{d x}\right)\left(\frac{d \theta}{d x}\right)\left(\frac{d^{2} \theta}{d x^{2}}\right)\right) d x+\int_{0}^{L} M_{y} \theta\left(\frac{d^{2} v}{d x^{2}}\right) d x+ \\
& \frac{1}{2} \int_{0}^{L}\left(q_{z} e_{z}(x) \theta^{2}\right) d x
\end{aligned}
$$

Where:

- $E I_{z}(x), G_{I T}(x), E I_{\omega}(x)$ are stiffnesses-respectively bent, torsional, and warped,

$-v$ and $\theta_{\mathrm{x}}$ are the lateral displacement and torsion angle,

- $M_{\mathrm{y}}$ is the moment of external forces,

$-q_{z}$ is the lateral load from distributed forces

- $e_{z}(x)$ is the distance from the shear center to the load application point, and

$-h(x)$ is the height of the cross-section.

The effectiveness of the ribs restraining the section depends on the constant $R_{\omega v}$ (see below), and also on the $I_{T S}$ torsional moment. The influence of ribs, located along the beam's length, on critical load values can be determined using the Rayleigh-Ritz method. The potential energy function (2) should be extended with an additional element (3), which takes into account the geometric and strength parameters of stiffening ribs. Due to the linearly changing web height along the beam length, the height of the stiffening ribs will also vary. Therefore, the elastic resistance coefficient depends on $\alpha_{T P}$.

$$
\Pi_{\omega}=\frac{1}{2} \sum_{\nu=1}^{n} R_{\omega \nu} \frac{\partial \theta_{x}^{2}}{\partial x}\left(x_{\nu}\right)^{2}
$$

where:

$-R_{\omega v}$ is the coefficient of elastic resistance:

$$
\begin{aligned}
& R_{\omega v}=G_{s} \times I_{T S} \times h_{s v} \\
& h_{s v}=h_{s 0}\left(1+\alpha_{T P} \frac{x_{v}}{L}\right)
\end{aligned}
$$

- $G_{S}$ is the lateral modulus of elasticity,

$-I_{T S}$ is the moment of inertia for twisting the stiffening rib,

$-h_{s v}$ is the rib height,

$-x_{n}$ is the location of rib $n$ along the beam, and

$-n_{v}$ is the number of stiffening ribs.

\section{SOLUTION FOR CRITICAL BUCKLING LOADS OF TAPERED I-BEAMS WITH STIFFENER RIBS}

The Rayleigh-Ritz method was used to determine the critical load which initiates torsional buckling of a beam with a coinciding web, and with vertical stiffening ribs. The discussion here provides only basic information on the application of the Rayleigh-Ritz method, insofar 
as is needed to obtain a solution for a bisymmetrical beam loaded with a uniformly distributed, continuous load. To obtain an approximate solution, the Ritz functions, describing displacements arising from bending and fulfilling boundary conditions, were expressed as sums of trigonometric functions:

$$
\begin{gathered}
v=\sum_{i=1}^{n} v_{i} \sin \left(i \pi \frac{x}{L}\right) \\
\theta_{x}=\sum_{i=1}^{n} \theta_{i} \sin \left(i \pi \frac{x}{L}\right)
\end{gathered}
$$

Using a finite number of terms $(6,7)$ replaces the continuous model with a discrete one. For practical engineering calculations for single-span, free-supported steel beams, the first-order approximation $(n=1)$ suffices.

To determine the critical moments of lateral-torsional buckling, we introduce a bending moment gradient function to describe how bending moments vary along the bar:

$$
m(x)=\frac{M_{e, E d(x)}}{M}, m(x)=\frac{4\left(\frac{x}{L}-\frac{x^{2}}{L^{2}}\right)}{M}
$$

Substituting the resistance coefficient (3) and boundary conditions into (2) yields the potential energy in a beam of the convergent cross-section. In matrix form, this is:

$$
\left[\begin{array}{cc}
k_{b b} & k_{b c} \\
s y m & k_{c c}
\end{array}\right]\left(\begin{array}{c}
v_{1} \\
\theta_{1}
\end{array}\right)=\left(\begin{array}{l}
0 \\
0
\end{array}\right)
$$

where:

$$
\begin{gathered}
k_{b b}=\frac{1}{2} \int_{0}^{L}\left(E I_{z}(x) \frac{\pi^{4} \sin ^{2}\left(\frac{\pi x}{L}\right)}{L^{4}}\right) \mathrm{d} x \\
k_{c c}=\frac{1}{2} \int_{0}^{L}\left(G I_{T}(x) \frac{\pi^{2} \cos ^{2}\left(\frac{\pi x}{L}\right)}{L^{2}}+E I_{\omega}(x) \frac{\pi^{4} \sin ^{2}\left(\frac{\pi x}{L}\right)}{L^{4}}\right) d x+ \\
\frac{1}{2} \int_{0}^{L}\left(E I_{Z}(x)\left(\left(\frac{\partial h(x)}{\partial x}\right)^{2} \frac{\pi^{2} \cos ^{2}\left(\frac{\pi x}{L}\right)}{L^{2}}\right)\right) d x+ \\
\frac{1}{2} \int_{0}^{L}\left(E I_{Z}(x)\left(h(x)\left(\frac{\partial h(x)}{\partial x}\right) \frac{\pi^{3} \sin ^{2}\left(\frac{2 \pi x}{L}\right)}{L^{3}}\right)\right) d x+\frac{1}{2} \sum_{v=1}^{n} R_{\omega v} \frac{\partial \theta x^{2}}{\partial x}\left(x_{v}\right)^{2} \\
k_{b c}=\bar{M} \int_{0}^{L}\left(\left(\frac{x}{L}-\frac{x^{2}}{L^{2}}\right) \frac{\pi^{2} \sin ^{2}\left(\frac{\pi x}{L}\right)}{L^{2}}\right) \mathrm{d} x
\end{gathered}
$$

The elements of the coefficient matrix (13) were obtained by determining the expressions, taking into account the taper parameter of the beam (1) and the geometric characteristics (Kuś, 2013). Finally, an approximate solution for critical moments initiating loss of ribbed, simply supported beam, loaded with uniformly distributed continuous load was obtained by setting the determinant to zero: 


$$
\operatorname{det}\left[\begin{array}{cc}
k_{b b} & k_{b c} \\
s y m & k_{c c}
\end{array}\right]=0
$$

Solving the matrix (13) due to $M$, gave critical moments that initiate loss of the stability of beam with linearly varying web height and vertical stiffening ribs distributed along the beam length. The presented solution was used in numerical examples.

\section{APPLICATION}

\subsection{Solution and checking calculations for prismatic beams with ribs}

In order to verify the correctness of the analysis above, critical load values were calculated as described, for a beam with taper parameter $\alpha_{\mathrm{tp}}=0$, and compared with solutions available in the literature. Three cases were considered: a prismatic beam without ribs $\left(n_{v}=0\right)$, one with stiffening ribs on supports $\left(n_{v}=2\right)$, and one with support ribs plus either two or four intermediate ribs $\left(n_{v}=4,6\right)$.

The beam was bisymmetric, with a span $L=6 \mathrm{~m}$, and initial cross-sectional parameters $h_{0}=$ $400 \mathrm{~mm}, b_{f o}=155 \mathrm{~mm}, t_{f}=22 \mathrm{~mm}, t_{w}=14.4 \mathrm{~mm}$ (I400). A continuous load was distributed evenly across the beam, applied to the upper flange $(g=-0.25 \mathrm{~m})$.

The calculations confirm the derived calculation formulae for critical buckling moments of torsional buckling for beams with web convergence parameter $\alpha_{\mathrm{TP}}=0$ (prismatic beam). The results do not differ by more than $1 \%$.

\subsection{Application to web-tapered I-beam with ribs}

The following example determines the critical buckling moments for a simply supported steel I-beam with a tapered web. The beam span is set variously to $6 \mathrm{~m}, 9 \mathrm{~m}$ and $12 \mathrm{~m}$. Its cross-sectional parameters are $h_{0}=300 \mathrm{~mm}, b_{f 0}=150 \mathrm{~mm}, t_{f}=10.7 \mathrm{~mm}$, $t_{w}=7.1 \mathrm{~mm}$.

Next, the ribbed beams with various numbers of ribs and linearly varying web height are analyzed. The load was applied to each of the upper flange, shear center, and lower flange. The web toe parameter was changed from $\alpha_{T P}=0$ (prismatic beam) to $\alpha_{T P}=1$ (web height at the right-hand end is twice as high as at the left-hand end). The same height change was used for the vertical stiffening ribs. The rib distributions for each case are shown in Figure 3.

The critical moment values are shown in Tables $2-4$. From the results of this parametric analysis, it can be concluded that the web tapering significantly increases the critical lateral-torsional buckling moments. Also, stiffening ribs elevate the critical buckling moments.

Table 1. Critical buckling load for prismatic I400 beam with and without ribs.

\begin{tabular}{lcccc}
\hline Critical point load [kN] & $n_{v}=0$ & $n_{v}=2$ & $n_{v}=4$ & $n_{v}=6$ \\
\hline Critical load by (Gosowski 2003) & 66.367 & 67.924 & 68.421 & 69.284 \\
Critical load by (Żmuda 2004) & 66.000 & 67.700 & 68.100 & 68.900 \\
Critical load by (Author) & 66.422 & 68.467 & 68.970 & 69.971 \\
Difference (Gosowski 2003 - & $0.08 \%$ & $0.79 \%$ & $0.81 \%$ & $0.99 \%$ \\
Author) & & & & \\
\hline
\end{tabular}



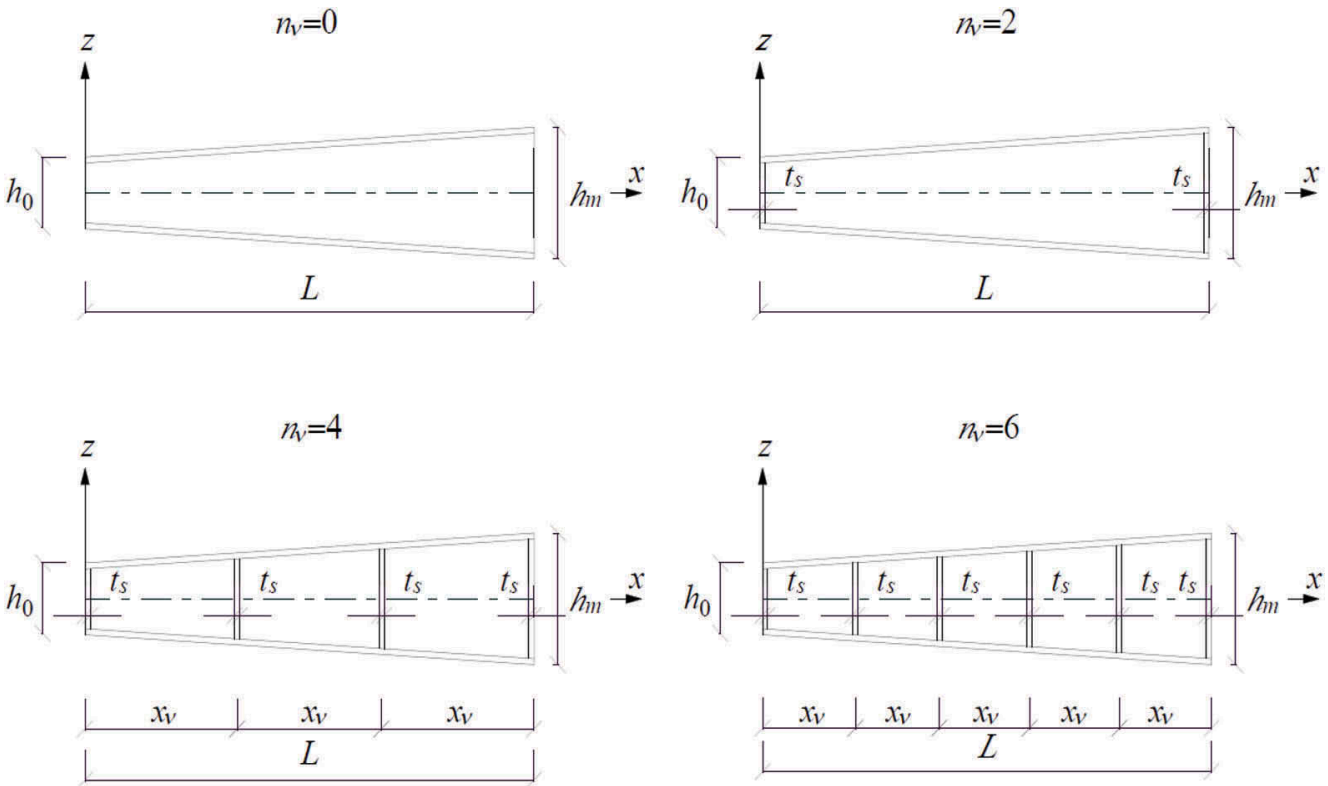

Figure 3. Tapered I-beam with stiffener ribs.

Table 2. Critical buckling moments for tapered I-beam with and without ribs; load on shear center.

\begin{tabular}{|c|c|c|c|c|c|c|}
\hline Load scheme & Number of ribs & Critical & ing momen & $\mathrm{Nm}]$ & & \\
\hline \multirow[t]{5}{*}{$q z$} & & $\alpha_{T P}=0$ & $\alpha_{T P}=0.4$ & $\alpha_{T P}=0.6$ & $\alpha_{T P}=0.8$ & $\alpha_{T P}=1.0$ \\
\hline & $n v=0$ & 86.630 & 94.320 & 98.781 & 103.583 & 108.681 \\
\hline & $n v=2$ & 99.866 & 108.897 & 113.872 & 119.102 & 124.439 \\
\hline & $n v=4$ & 102.91 & 112.245 & 117.341 & 122.676 & 128.219 \\
\hline & $n v=6$ & 108.74 & 118.659 & 123.990 & 129.527 & 135.246 \\
\hline
\end{tabular}

Table 3. Critical buckling moments for tapered I-beam with and without ribs; load on top flange.

\begin{tabular}{|c|c|c|c|c|c|c|}
\hline Load scheme & \multirow[t]{2}{*}{ Number of ribs } & \multicolumn{5}{|c|}{ Critical buckling moment $[\mathrm{kNm}]$} \\
\hline \multirow{5}{*}{$e_{z}(x)$} & & $\alpha_{T P}=0$ & $\alpha_{T P}=0.4$ & $\alpha_{T P}=0.6$ & $\alpha_{T P}=0.8$ & $\alpha_{T P}=1.0$ \\
\hline & $n v=0$ & 64.374 & 68.299 & 70.825 & 73.760 & 76.940 \\
\hline & $n v=2$ & 77.119 & 82.242 & 85.261 & 88.532 & 92.023 \\
\hline & $n v=4$ & 80.067 & 85.466 & 88.594 & 91.958 & 95.528 \\
\hline & $n v=6$ & 85.728 & 91.662 & 95.002 & 98.549 & 102.277 \\
\hline
\end{tabular}

Consider, for example, the results for the beam with its bottom flange loaded (Table 4). For the tapering parameters $\alpha_{\mathrm{TP}}=1$ and number of ribs $n_{\mathrm{v}}=6$, the critical moments, with respect to the beam without ribs, increase by approximately $14 \%$. 
Table 4. Critical buckling moments for tapered I-beam with and without ribs; load on bottom flange.

\begin{tabular}{|c|c|c|c|c|c|c|}
\hline \multirow[t]{2}{*}{ Load scheme } & \multirow[t]{2}{*}{ Number of ribs } & \multicolumn{5}{|c|}{ Critical buckling moment $[\mathrm{kNm}]$} \\
\hline & & $\alpha_{T P}=0$ & $\alpha_{T P}=0.4$ & $\alpha_{T P}=0.6$ & $\alpha_{T P}=0.8$ & $\alpha_{T P}=1.0$ \\
\hline \multirow{4}{*}{$e_{z}(x)$} & $n v=0$ & 116.474 & 130.176 & 137.55 & 145.308 & 153.349 \\
\hline & $n v=2$ & 129.219 & 144.065 & 151.946 & 160.080 & 168.433 \\
\hline & $n v=4$ & 132.166 & 147.290 & 155.280 & 163.506 & 171.938 \\
\hline & $n v=6$ & 137.828 & 153.485 & 161.688 & 170.097 & 178.686 \\
\hline
\end{tabular}

\section{CONCLUSIONS}

The solution proposed here provides a way to determine the critical moments that initiate torsional buckling of ribbed beams with tapered cross-sections, for different taper angles. Calculations show that changing the taper parameters significantly affects the critical moments. The increase in the critical moments of a beam with a tapered web $\left(\alpha_{T P}=1\right)$ compared to a prismatic beam $\left(\alpha_{T P}=0\right)$ was about $20 \%$. As expected, beams with slender webs are more sensitive to loss of stability. However, the use of stiffening ribs increased the critical moments compared to beams without it.

\section{REFERENCES}

Andrade A., Camotim D., Borges Dinis P. 2007. Lateral-torsional buckling of singly symmetric web-tapered thin-walled I-beams: 1D model vs. Shell FEA, Computers and Structures. vol. $85,1343-1359$.

Abdelrahmane Bekaddour Benyamina, Sid Ahmed Meftah, Foudil Mohri, El Mostafa Daya. 2013. Analytical solutions attempt for lateral-torsional buckling of double symmetric web-tapered I-beams, Engineering Structures. vol. 56, 1207-1219.

Asgarian B., Soltani M., Mohri F. 2001. Lateral-torsional buckling of tapered thin-walled beams with arbitrary cross-sections, Thin-walled structures. vol. 62, 96-108.

Gosowski B. 2003. Spatial stability of braced thin-walled members of steel structures, Journal of Constructional Steel Research, vol. 59, 839-865.

Gosowski B. 2007. Non-uniform torsion of stiffened open thin-walled members of steel structures, Journal of Constructional Steel Research, vol. 63, 849-865.

Kuś J. 2013. Analysis of stability of beams with converging cross-sections, PhD thesis, Faculty of Construction, Technical University of Opole. 1-92, Opole.

Kuś J. 2015. Lateral-torsional buckling steel beams with simultaneously tapered flanges and web, Steel Composite Structures An International Journal, vol.19, 897-916.

Lindener J. 1996. Influence of constructional details on the load carrying of beams, Engineering Structures, vol. 11, 752-758.

Trahair N. S. 1993. Flexural-Torsional Buckling of Structures, E and F. N. Spon, London.

Trahair N. S. 2014. Bending and buckling of tapered steel beam structures, vol. 59, 229-237.

Żmuda J. 2004. Problems of instability in designing steel girders, Studies and Monographs, no.156, Opole University of Technology Publishing Office, Opole (in Polish). 